\title{
Dispersal and habitat cuing of Eurasian red squirrels in fragmented habitats
}

\author{
Lucas Armand Wauters • Goedele Verbeylen • \\ Damiano Preatoni · Adriano Martinoli • \\ Erik Matthysen
}

Received: 3 September 2009/ Accepted: 14 January 2010

(C) The Society of Population Ecology and Springer 2010

\begin{abstract}
Animal dispersal and subsequent settlement is a key process in the life history of many organisms, when individuals use demographic and environmental cues to target post-dispersal habitats where fitness will be highest. To investigate the hypothesis that environmental disturbance (habitat fragmentation) may alter these cues, we compared dispersal patterns of 60 red squirrels (Sciurus vulgaris) in three study sites that differ in habitat composition and fragmentation. We determined dispersal distances, pre- and post-dispersal habitat types and survival using a combination of capture-mark-recapture, radiotracking and genetic parentage assignment. Most (75\%) squirrels emigrated from the natal home range with mean dispersal distance of 1,014 $\pm 925 \mathrm{~m}$ (range 51-4,118 m). There were no sex-related differences in dispersal patterns and no differences in average dispersal distance, and the proportion of dispersers did not differ between sites. In one of the sites, dispersers settled in patches where density was lower than in the natal patch. In the least fragmented site, $90 \%$ of animals settled in the natal habitat type (habitat cuing) against $44-54 \%$ in the more strongly fragmented sites. Overall, more squirrels settled in the natal habitat type than expected based on habitat availability, but this
\end{abstract}

L. A. Wauters $(\bowtie) \cdot$ D. Preatoni · A. Martinoli Department of Environment, Health and Safety, University of Insubria, Via J.H. Dunant 3, 21100 Varese, Italy e-mail: 1.wauters@uninsubria.it

L. A. Wauters - G. Verbeylen · E. Matthysen Evolutionary Ecology Group, Deparment of Biology, University of Antwerp, Groenenborgerlaan 171, 2020 Antwerp, Belgium

Present Address:

G. Verbeylen

Natuurpunt Studie, Coxiestraat 11, 2800 Mechelen, Belgium was mainly due to individuals remaining within the natal wood. In the highly fragmented landscape, habitat cuing among emigrants did not occur more frequently than expected. We concluded that increased habitat fragmentation seemed to reduce reliable cues for habitat choice, but that dispersing squirrels settled in patches with lower densities of same-sex animals than at the natal home range or patch, independent of degree of fragmentation.

Keywords Dispersal distance - Habitat quality · Landscape composition - Natal habitat-biased dispersal . Parentage assignment $\cdot$ Sciurus vulgaris

\section{Introduction}

Animal dispersal, commonly defined as a one-way movement of individuals causing population redistribution (Turchin 1998), is a key process in the life history of many organisms, involved in species persistence, distribution and evolution (Clobert et al. 2001). Since dispersal has a 'bottom-up' effect, it not only affects an individual's fitness (probability to survive the dispersal process and to settle in a habitat that enhances reproductive success), but also (meta)population dynamics, gene flow (and thus genetic diversity within and between populations), colonisation of habitat patches, and species distribution (Stenseth and Lidicker 1992; Wiens et al. 1993; Turchin 1998; Clobert et al. 2001; Vuilleumier and Fontanillas 2007).

Among birds and mammals, dispersal mostly takes place in the immature stage, before first reproduction, i.e., natal dispersal (Greenwood 1980; Wolff 1994; Hanski and Selonen 2009). In general, there are three possible stages. First, an immature animal starts to explore areas around the nest and subsequently will leave the natal area, which in 
birds and mammals often coincides with the parental home range. Second, the transient event occurs in the form of movements across habitats. And third, an arrival event when the individual establishes a home range in an area where it will attempt to reproduce (Larsen and Boutin 1994; Haughland and Larsen 2004a; Locey and Stone 2008; Hanski and Selonen 2009). During this dispersal and settlement process, animals use local demographic (local density and thus competition pressure by conspecifics) and environmental cues (Wauters and Dhondt 1993; Lima and Zollner 1996; Matthysen 2005) that are likely to interact with an individual's phenotype and life history (Dobson and Jones 1985; Haughland and Larsen 2004a, b). Theoretically, dispersers should use such cues to target the habitat where fitness will be highest. Individuals originating from a particular habitat might perform better if they, for innate or experience-based reasons, disperse to a habitat similar to that where they were born, a tactic called 'natal habitat-biased dispersal' (Stamps 1987; Davis and Stamps 2004; Haughland and Larsen 2004a, b; Selonen et al. 2007).

However, increased environmental variation, for example induced by man-made landscape changes, such as the fragmentation of suitable or high-quality habitats, may alter or even eliminate the cues animals use to select habitats during dispersal and settlement, which can reduce the animals' ability to optimise fitness (Lima and Zollner 1996; Remeš 2000; Schlaepfer et al. 2002). Hence, studying dispersal behaviour of individuals in landscapes that differ in habitat composition, structure and amount of fragmentation is essential to improve our ability to successfully predict how (meta)populations will respond to changes in habitat-heterogeneity (a long-standing goal of theoreticians, wildlife and habitat managers and conservationists; Pulliam and Danielson 1991; Garshelis 2000; Travis and French 2000). Because of the difficulty of following mobile animals, most studies that directly monitor dispersal behaviour and the outcome (success) of dispersal are limited to a single (meta)population (Larsen and Boutin 1994; Matthysen et al. 1995; Byrom and Krebs 1999; Schiegg et al. 2006; Szulkin and Sheldon 2008), while studies which have compared dispersal among landscapes of different structure are still limited (e.g., nuthatches, Matthysen and Currie 1996; ferrets, Byrom 2002; flying squirrels, Selonen et al. 2007; Florida scrub-jay, Coulon et al. 2008; roe deer, Gaillard et al. 2008).

A species that is relatively amenable to study natal dispersal over a range of landscapes that differ in the degree of fragmentation is the Eurasian red squirrel (Sciurus vulgaris). Red squirrels are promiscuous and adult females defend intrasexual territories while males have overlapping home ranges with a dominance hierarchy (Wauters et al. 1990; Wauters and Dhondt 1992). Site fidelity is high and important to reproductive success, and most parents produce several litters in a lifetime (Wauters and Dhondt 1995; Wauters et al. 1995). Indirect studies of dispersal, using immigration patterns and characteristics of immigrants, indicated that dispersal tendency in both sexes depends on the degree of intrasexual competition under local conditions (Wauters and Dhondt 1993; Wauters et al. 1994a). Comparing survival and lifetime reproductive success in dispersing and resident red squirrels further suggested that decisions related with how far to disperse and where to settle are not adaptive choices but rather the outcome of local competition, supporting the Resident Fitness Hypothesis (Anderson 1989; Wauters et al. 1994b). However, no studies have directly monitored the dispersal behaviour of the species, and data on the distribution of dispersal distances are lacking. Moreover, indirect data to date have been mainly gathered in relatively large forests and little is known about the effects of forest fragmentation on dispersal behaviour and success (Wauters et al. 1994a, c).

The aim of this study was to examine the dispersal process and related characteristics, such as dispersal distances, settlement habitat and survival after dispersal in red squirrel populations. We monitored 60 individuals by capture-mark-recapture and/or radio-tracking. In particular, we explored whether the average and range of dispersal distances were affected by degree of habitat fragmentation, and whether the animals would be more likely to settle in a habitat similar to the natal habitat than in a different habitat. However, when habitats were strongly altered (forest fragmentation in our case), the proportion of dispersers settling in such a habitat was predicted to be lower. In addition to testing these predictions, we answered why immigration rates were lower in fragments than in large, contiguous forests (Wauters et al. 1994a), by examining the following mutually non-exclusive explanations: (1) a higher proportion of juveniles settles near their natal home range in fragments;and (2) survival during and after dispersal is lower in fragments than in large forests (see also Matthysen and Currie 1996).

\section{Materials and methods}

\section{Study sites}

We monitored red squirrels in three study sites in N. Belgium that differed in size, degree of connectivity between woodland plots, and matrix habitat (Table 1). Woodland patches distant less than $10 \mathrm{~m}$ were joined into a single patch before measuring landscape features. Spatial parameters and patch features were calculated using FRAGSTATS software (McGarigal and Marks 1994). 
Table 1 Spatial parameters of the study sites and patch features, calculated using Fragstats (McGarigal and Marks 1994)

\begin{tabular}{|c|c|c|c|}
\hline \multirow[t]{2}{*}{ Parameters } & \multicolumn{3}{|l|}{ Study site } \\
\hline & $\mathrm{CON}$ & KH & SKW \\
\hline Overall size (ha) & 2,827 & 1,977 & 4,590 \\
\hline Coordinates & $51^{\circ} 08^{\prime} \mathrm{N}, 4^{\circ} 43^{\prime} \mathrm{E}$ & $51^{\circ} 10^{\prime} \mathrm{N}, 4^{\circ} 38^{\prime} \mathrm{E}$ & $51^{\circ} 05^{\prime} \mathrm{N}, 4^{\circ} 34^{\prime} \mathrm{E}$ \\
\hline Study plot (ha) & 30 & 55 & 15 patches $>3.5$ \\
\hline Mean WQ & 91 & 62 & 22 (range $0.4-55.8$ ) \\
\hline Mean adult density $\left(\mathrm{ha}^{-1}\right)$ & 1.12 & 0.52 & $0.1-0.7^{\mathrm{a}}$ \\
\hline Study period & 1991-1992 & 1992-1993 & 1993-1999 \\
\hline Food abundance $\left(10^{3} \mathrm{~kJ} / \mathrm{ha}\right)^{\mathrm{b}}$ & $1,457,597$ & $560(1992)$ & $10,405,1,207,1,851,1,239$ \\
\hline \multicolumn{4}{|l|}{ Spatial parameters } \\
\hline Covered by forest (ha) (\%) & $590.86(20.9)$ & $365.55(18.5)$ & $290.38(6.2)$ \\
\hline Number of patches & 73 & 56 & 63 \\
\hline Patches $>10$ ha & 9 & 6 & 8 \\
\hline Patches $<10$ ha & 64 & 50 & 55 \\
\hline Edge density $(E D)^{\mathrm{c}}$ & 183 & 247 & 275 \\
\hline Mean proximity index (MPI) ${ }^{\mathrm{d}}$ & 993 & 146 & 42 \\
\hline Mean patch size (ha) (range) & $8.09(0.34-315.46)$ & $6.53(0.43-179.74)$ & $4.61(0.15-57.10)$ \\
\hline Mean distance to nearest patch (m) (range) & $97(16-614)$ & $89(12-353)$ & $186(36-1,005)$ \\
\hline Mean distance to nearest patch $>10$ ha $(\mathrm{m})$ (range) & $111(22-1,231)$ & $200(54-1,645)$ & $815(51-2,547)$ \\
\hline
\end{tabular}

Buffer size was determined using a circle of $3 \mathrm{~km}$ radius around the centre of the study plot (CON, $\mathrm{KH})$ and/or man-made barriers such as canals, busy roads or urban centers $(\mathrm{KH}, \mathrm{SKW})$. Study plot for $\mathrm{CON}$ and $\mathrm{KH}$ were in the largest patch

For details on SKW see "Materials and methods"

$W Q$ Woodland quality index; mean adult density number of adult squirrels present in July

a Variation in density affected by patch quality, from Fig. 6 in Verbeylen et al. (2003)

${ }^{\text {b }}$ G. Verbeylen (unpublished data) of seed-crop size based on annual seed counts in sampling plots (1996-1999, respectively, in SKW)

${ }^{c}$ Edge density (ED in $\mathrm{m} / \mathrm{ha}$ ) increases when landscape becomes more fragmented in smaller habitat patches

${ }^{d}$ Mean proximity index (MPI; McGarigal and Marks 1994) increases as patches become less isolated

Distances between neighbouring patches were calculated using the Nearest features (nearfeat.avx) estension for ArcView 3.x v. 3.8b (Jenness 2007).

Site CON had the highest forest cover and largest forest patch (315 ha; Table 1). The 30-ha study plot was part of a mixed conifer forest dominated by seed-bearing Scots pine, Pinus sylvestris, and Corsican pine, Pinus nigra var. calabrica (72\%), some larch, Larix decidua (4\%), mature common oak, Quercus robur, and beech, Fagus sylvatica $(15 \%)$, and young mixed woodland $(9 \%)$. The woodland fragment, KH (Table 1), was a partly forested moorland with dense stands of young and mature Scots and Corsican pine, birch, Betula sp., and oak, and open areas with few Scots pine and birch (site H in Wauters et al. 1994a). The highly fragmented landscape (SKW) consisted of a group of 63 woodland fragments (hereafter "patches") between 0.15 and 57 ha, with 15 patches larger than 3.5 ha, the minimum size for occupation by squirrels in this landscape (Verbeylen et al. 2003). Patches covered only $6.2 \%$ of the total study area (Table 1; details of matrix habitat, patch size and distribution in Verbeylen et al. 2003). Main food trees were common oak (25\% for all patches), Corsican pine (7\%), Norway spruce, Picea abies (5\%), Scots pine (4\%), beech (3\%), larch (2\%), and sweet chestnut, Castanea sativa (2\%). In all patches, squirrels had access to hazel, Corylus avellana, shrubs. In each study site, woodland quality (WQ; Table 1) was estimated as the sum of the percentage of important food-producing trees for squirrels (Scots and Corsican pine, Norway spruce, oak, beech, larch, and sweet chestnut; see also Wauters et al. 1994a; Verbeylen et al. 2003, 2009).

In $\mathrm{CON}$ and $\mathrm{KH}$, all squirrels were marked in the same woodland. Distance to the nearest patch was $85 \mathrm{~m}$ in CON and $59 \mathrm{~m}$ in $\mathrm{KH}$. In SKW, distance to the nearest patch, for patches from where squirrels emigrated, varied between 311 and $774 \mathrm{~m}$ (mean $\pm \mathrm{SD}=526 \pm 191 \mathrm{~m})$.

Study periods varied among sites. Food abundance, expressed as seed-crop size of food-producing trees (see Wauters et al. 2004 for seed count methods), varied between sites and over years (Table 1). In CON, conifers produced a mast-crop in 1991 and a medium seed-crop in 1992, while in SKW food abundance varied over years with a mast crop (oak and beech; G. Verbeylen, unpublished data) in 1996 and medium seed-crops in 1997-1999 (Table 1). 
Population monitoring

Populations were monitored using capture-mark-recapture (CMR) and radio-tracking. We trapped squirrels with wooden box $(55 \times 17 \times 17 \mathrm{~cm})$ and Tomahawk live traps ('squirrel model' $41 \times 14 \times 14 \mathrm{~cm}$; Tomahawk Live Trap, Tomahawk, WI, USA). Traps were pre-baited with hazelnuts for 2-3 days, and baited and set for 1-2 weeks (Wauters and Dhondt 1993). Trapping was carried out bimonthly in 1991-1997, while in SKW this was reduced to once every 4 months in 1998-1999 (Wauters et al. 1994a, b, 2004; Verbeylen et al. 2003). Traps were set in the morning and checked twice a day. Trapped squirrels were flushed into a zipper-tube and individually marked using numbered metal ear-tags (type 1003 S, 10 by 2 mm; National Band and Tag, Newport, Kentucky, USA) or with transponders (PIT tags; Fish eagle Int., UK). They were weighed to the nearest $5 \mathrm{~g}$ using a spring-balance (Pesola, Baar, Switzerland). Sex, age and reproductive condition were recorded following Wauters and Dhondt (1995). Pregnant and/or lactating females were radio-collared using SR-1 and TW-4 transmitter collars ( $\pm 12 \mathrm{~g}, 9$ and 18 months lifetime, respectively; Biotrack, Wareham, UK) to locate the nursing nest (Wauters and Dhondt 1995). We used the minimum number of animals known to be alive (MNA), from trapping, radio-tracking or observations, as our estimate of population density (Verbeylen et al. 2003, 2009; Wauters et al. 2004). This allowed us to determine densities encountered before and after dispersal for those squirrels that left the natal woodland in site SKW.

\section{Determining natal home range}

We used three ways to determine the natal home range or natal woodland (SKW) for 60 squirrels.

Firstly, 27 juveniles (CON 8 animals, KH 9, SKW 10) were marked in the nursing nest or trapped at the nest tree. All juveniles from $\mathrm{CON}$ and $\mathrm{KH}$, and five from SKW were recaptured and radio-collared when ca. 10-14 weeks old, when they weighed between 160 and $230 \mathrm{~g}$ (SR-1 transmitter collars, $\pm 6 \mathrm{~g}$, or approximately $3 \%$ of a juvenile's body mass; Biotrack). The other five from SKW were monitored by recaptures either in the natal or in a different patch. Secondly, for 19 juveniles and subadults in SKW, natal patch was determined using maternity assignment in CERVUS 2.0 (Marshall et al. 1998). DNA was extracted from ear tissue (3 $\mathrm{mm}$ biopsy punch) using a standard phenol-chloroform protocol (for details, see Trizio et al. 2005). Individuals were genotyped at 13 microsatellite loci (GeneBank accession numbers AF309452, AF309455, AF309456, AF309457, AF309458, AF309462, AF309463 and AF309466; Hale et al. 2001; and GeneBank accession numbers from AF285149 to AF285153; Todd 2000), polymerase chain reaction (PCR), amplifications and analysis of PCR products as described in Trizio et al. (2005). Maternity was assigned at 95 and $80 \%$ confidence. Input parameters for the simulation step of CERVUS were as follows: 10,000 cycles, between 20 and 47 candidate mothers, $95 \%$ of the population sampled, $72 \%$ of all loci genotyped (between 7 and 13 loci) and 1\% genotyping error allowed. Separate analyses were conducted for each year (1995-1999). Fourteen animals were monitored after the first capture using CMR and radio-tracking, and five only by CMR. Thirdly, 14 squirrels (CON 2, SKW 12), weighing $>250 \mathrm{~g}$ at first capture (subadults), with abdominal testis and small, unstained scrotum (males), or a small, unperforated vulva and no visible nipples (females), were classified as transients engaged in dispersal (Wauters and Dhondt 1993). They were monitored using radio-tracking (SR-1 and TW-4 transmitter collars, $12 \mathrm{~g}, 9$ and 18 months lifetime, respectively; Biotrack) and CMR (in SKW). Although their natal home range was not exactly known, these squirrels did not have shorter dispersal distances than animals with known natal range (mean distance \pm SD: unknown natal range $1,333 \pm 1,037 \mathrm{~m}$, known natal range $917 \pm 877, t_{58}=1.49, P=0.14$ ), thus including them in our analyses did not reduce our estimates.

\section{Natal dispersal data}

During the dispersal process, behaviour of juvenile tree squirrels can be divided into distinct phases (Larsen and Boutin 1994; Haughland and Larsen 2004b; Hanski and Selonen 2009). Young start moving around their natal nest and gradually become independent of their mother at the age of 6 to 10-12 weeks old. Before dispersal, some animals make exploratory movements outside the natal area returning by evening. The time period spent at or near the natal home range varies among individuals (from 3-4 to 7-10 months of age; see also Wauters and Dhondt 1993; Wauters et al. 1994a). After the dispersal movement period, juveniles or subadults settle at a new home range, or behave as floaters (Wauters and Dhondt 1992; Wauters et al. $1994 \mathrm{~b}, \mathrm{c})$.

We considered a squirrel settled when it cached tree seeds (Wauters and Casale 1996) and/or remained in the same, restricted area (the post-dispersal home range) for at least 3 months after ending its dispersal movements. Since strict philopatry, i.e., settling on the maternal home range, hardly occurred (Wauters and Dhondt 1993), 'local recruits' were young that established residency in a home range, within the woodland or patch in which they were born, of which the centre was less than $350 \mathrm{~m}$ away from the centre of their natal home range (adapted from Wauters et al. 1994b; based on home range sizes in our study areas). Since this is less than twice the diameter of the natal home 
range (based on average home range size of adult female of 2.5-3.1 ha; Wauters and Dhondt 1992), a local recruit's home range on average overlapped with a home range adjacent to the natal range. Emigrants had their post-dispersal home range spatially separated from the natal range (with centre $>350 \mathrm{~m}$ from that of natal range) and/or dispersed to a different wood.

Survival before and after dispersal was monitored using CMR and radio-tracking data (Larsen and Boutin 1994). Survival was a binary variable (scored 1 when a squirrel survived for $\geq 6$ months after dispersal, scored 0 when it did not survive this period). Survival probability for local recruits and emigrants was examined by logistic regression (Hosmer and Lemeshow 1989), exploring the effects of site, sex, age, fate, habitat, wood, distance and post-dispersal habitat quality and the site $\times$ sex and site $\times$ fate interactions. Models were calculated by stepwise forward selection of significant independent variables $(\alpha=0.05$; Proc genmod with Wald Type $3 \chi^{2}$; SAS 1999). Applying stepwise backward model selection starting from a full model containing all variables and the interactions did not change the results. All tests of significance are two-tailed and the significance level was set at 0.05. Unless otherwise indicated values are presented in the text as mean \pm SD.

\section{Dispersal distances}

Dispersal distance was calculated for 60 squirrels (32 males, 28 females) as the Euclidean distance between home range centres (recalculated arithmetic mean of MCP) of pre- and post-dispersal home range, or the Euclidean distance from the centre of the pre-dispersal home range, a trap site or the nest site, to the location where dispersers were last detected (Larsen and Boutin 1994). For these animals, we also determined whether they remained within or left the woodland of the natal range, and if the habitat type at the post-dispersal range was the same or different than at the natal range (habitat type, $1=$ same, $2=$ different). Four habitat types were defined: pine dominated ( $>50 \%$ mature conifers), deciduous ( $>50 \%$ seed-bearing deciduous food trees), mixed wood, and marginal habitats (>60\% young trees or non-food species), and their availability was calculated in each study site (Table 2). Finally, in sites CON and SKW (>1-year data), we used a general linear model (GLM) to explore effects of food availability (dispersal in years with mast-crop, 1991 in CON and 1996 in SKW, against dispersal in years with lower food abundance), study site and the site $\times$ food interaction on dispersal distances.

\section{Results}

Dispersal distances

Mean dispersal distance $( \pm \mathrm{SD})$ was $1,014 \pm 925 \mathrm{~m}$ ( $n=60$; range $51-4,118 \mathrm{~m}, \mathrm{IQR}=323-1,515 \mathrm{~m}$ ). The median was $678 \mathrm{~m}$. Average dispersal distance did not differ between males and females or between sites (Table 3; GLM sex $F_{1,54}=0.39 ;$ site $F_{2,54}=0.98$; sex $\times$ site $F_{2,54}=0.01$, all $\left.P>0.30\right)$. Likewise, there were no differences of the distance distributions between sites (2-sample Kolmogorov-Smirnov test: CON-KH $D=0.171, P=0.98$; CON-SKW $D=0.337, P=0.32$; KH-SKW $D=0.356, P=0.54$; Fig. 1). Nevertheless, in $\mathrm{CON}$ no squirrels and in $\mathrm{KH}$ only one squirrel moved $>2 \mathrm{~km}$ from the natal range, while in SKW seven squirrels (17\%) dispersed $>2 \mathrm{~km}$ (Fig. 1).

Variation in dispersal distance was not affected by woodland quality in the natal range $\left(F_{1,47}=0.56\right.$,

Table 2 Percentage habitat types per study site

\begin{tabular}{lllcc}
\hline Site & Pine dominated woods & Deciduous woods & Mixed woods & Marginal habitats \\
\hline CON & $48.9(8 / 9)$ & $26.2(0)$ & $3.9(1 / 1)$ & $21.0(0)$ \\
KH & $10.3(0 / 2)$ & $25.7(0)$ & $17.6(4 / 7)$ & $46.4(0)$ \\
SKW & $14.4(11 / 17)$ & $37.4(6 / 13)$ & $26.1(4 / 7)$ & $22.1(1 / 4)$ \\
\hline
\end{tabular}

The number of squirrels that settled in the natal habitat type out of the number born in each natal habitat type are shown in parentheses

Table 3 Dispersal distances (m) of red squirrels (mean \pm SD) per study site and sex

\begin{tabular}{lccc}
\hline Site & Males $(n=32)$ & Females $(n=28)$ & Both $(n=60)$ \\
\hline CON & $564 \pm 555(n=6)$ & $763 \pm 759(n=4)$ & $643 \pm 611(n=10)$ \\
KH & $802 \pm 916(n=3)$ & $1,044 \pm 689(n=6)$ & $963 \pm 722(n=9)$ \\
SKW & $1,049 \pm 1,097(n=23)$ & $1,201 \pm 921(n=18)$ & $1,116 \pm 1,014(n=41)$ \\
Total & $935 \pm 998$ & $1,104 \pm 843$ & \\
\hline
\end{tabular}


Fig. 1 Distribution of dispersal distances (count number of individuals) of red squirrels in three study sites with different degree of forest fragmentation (see Table 1)

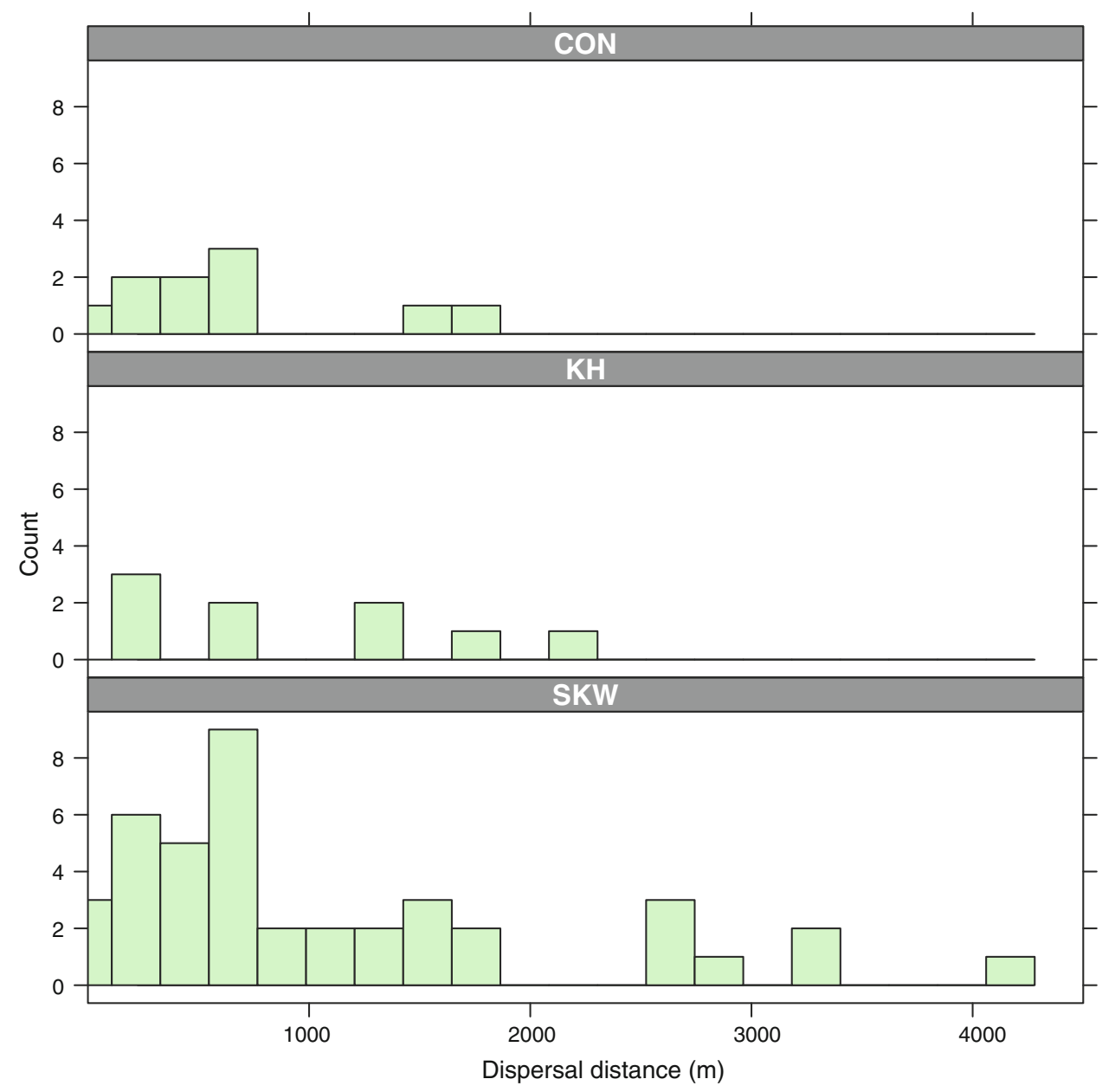

$P=0.46)$ or in the post-dispersal range $\left(F_{1,47}=0.11\right.$, $P=0.75)$. Also, there was no relationship between dispersal distance and difference in woodland quality before and after dispersal $\left(F_{1,47}=0.59, P=0.45\right)$. We found no interactions of study site with $\operatorname{sex}\left(F_{2,52}=0.04, P=0.96\right)$ or with habitat type $\left(F_{2,50}=0.71, P=0.50\right)$, and no effect of study site $\left(F_{2,54}=0.47, P=0.63\right)$. Hence, average dispersal distance was not affected by different degrees of fragmentation between study sites.

Overall, squirrels that settled in a habitat different from the natal area moved over longer distances than animals that did not change habitat type (average dispersal distance: same habitat $695 \pm 697 \mathrm{~m}, \quad n=36$; different habitat $1,492 \pm 1,029 \mathrm{~m}, \quad n=24$; habitat effect $P=0.0019)$. However, there was a habitat $\times$ sex interaction $\left(F_{1,54}=\right.$ $6.95, P=0.011$, sex-effect $F_{1,54}=0.01, P=0.92$ ). Males which changed habitat type moved over longer distances than those that settled in the natal habitat type $(n=21$, $1,823 \pm 1,204 \mathrm{~m}$ against $n=11,470 \pm 399 \mathrm{~m}$, respectively, $P<0.0001$ ), while for females this was not the case (different habitat $n=13,1,212 \pm 797 \mathrm{~m}$, same habitat $n=15,1,011 \pm 897 \mathrm{~m}, P=0.62)$.
Dispersal distance was not affected by yearly variation in food abundance (mast-crop against lower seed-crop, $\left.F_{1,47}=0.89, P=0.35\right)$ and there was no food $\times$ site interaction $\left(F_{1,46}=0.28, P=0.60\right)$. In mast and non-mast years, dispersal distances were, respectively, $488 \pm 676 \mathrm{~m}$ $(n=6)$ and $881 \pm 482 \mathrm{~m}(n=4)$ in CON, and $860 \pm 777 \mathrm{~m}(n=15)$ and $1,263 \pm 1,116 \mathrm{~m}(n=26)$ in SKW.

\section{Emigration patterns}

We used a hierarchical loglinear model to explore the effects of study site, sex, fate $(1=$ local recruits, $2=$ dispersers) and their interactions on the number of squirrels that settled in or near the natal home range (local recruits) against the number that dispersed (Proc genmod with binomial error distribution and WaldType3 Chisquare; SAS 1999). The majority of juveniles or subadults dispersed (45 of $60,75 \%$; fate $\chi^{2}=7.76, d f=1$, $P=0.005)$. Neither the 3 -way interaction $\left(\chi^{2}=2.08\right.$, $d f=2, \quad P=0.35)$ nor 2-way interactions with fate $\left(\right.$ sex $\times$ fate $\chi^{2}=1.56, \quad d f=1, \quad P=0.21 ; \quad$ site $\times$ fate 
Table 4 Percentage of squirrels dispersing away from the natal home range and percentage of squirrels settling in a habitat type similar to the natal habitat according to sex and study site (sample sizes as in Table 3)

\begin{tabular}{|c|c|c|c|c|}
\hline \multirow[t]{2}{*}{ Site } & \multicolumn{2}{|c|}{ Percentage dispersing squirrels } & \multicolumn{2}{|c|}{ Percentage settling in natal habitat-type } \\
\hline & Males & Females & Males & Females \\
\hline $\mathrm{CON}$ & 50 & 75 & 83 & 100 \\
\hline KH & 33 & 83 & 67 & 33 \\
\hline SKW & 78 & 83 & 61 & 50 \\
\hline
\end{tabular}

$\left.\chi^{2}=2.68, d f=2, P=0.26\right)$ were significant, indicating that similar proportions of males and females dispersed and that proportion dispersers did not differ between sites (Table 4).

Overall, habitat quality in the woodland where squirrels were found after dispersal was not higher than in the natal site (difference in habitat quality $=-2.7 \pm 18.9 \%$; $n=60$; range -57 to $+38 \%$; $t$ test for mean different from $0 t=-1.10, P=0.27)$.

In $\mathrm{CON}$ and $\mathrm{KH}$, no emigrants leaving the natal woodland settled in the nearest patch. In the strongly fragmented landscape SKW, patterns differed. Nine of 25 emigrants $(36 \%)$ leaving the natal woodland dispersed to the nearest patch (Fisher Exact comparing $\mathrm{CON}$ and $\mathrm{KH}$ against SKW, $P=0.073)$.

Natal habitat type imprinting?

To investigate whether natal habitat type affected where squirrels settled, we tested effects of post-dispersal habitat type (same vs different to natal habitat), study site, sex, and their interactions on number of dispersing squirrels. Overall, 35 squirrels $(58 \%)$ settled in the natal habitat type. There was no significant 3 -way interaction $\left(\chi^{2}=0.27\right.$, $d f=2, \quad P=0.60)$, no sex $\times$ habitat type interaction $\left(\chi^{2}=2.12, \quad d f=1, \quad P=0.15\right) \quad$ and no sex effect $\left(\chi^{2}=0.37, d f=1, P=0.54\right)$. Hence, similar proportions of males and females settled in the natal habitat type (males 21 out of $32,66 \%$; females 14 out of $28,50 \%$ ). Proportions of squirrels settling in the natal habitat tended to vary among sites (site $\times$ habitat-type interaction $\chi^{2}=5.44$, $d f=2, P=0.066$; Table 4): in CON, $90 \%$ of animals settled in the natal habitat type against $54 \%$ in SKW and only $44 \%$ in $\mathrm{KH}$. In site $\mathrm{KH}$, settlement in the natal habitat type did not differ from expected based on percentage habitat availability, but in CON and SKW, more animals than expected settled in the natal habitat type (Table 2, One-sample goodness-of-fit tests, $d f=1$, and Yates correction where appropriate, $\mathrm{KH} \chi^{2}=3.43, P>0.05$; $\mathrm{CON}$ $\chi^{2}=6.68, P<0.01$; SKW $\left.\chi^{2}=19.1, P<0.01\right)$, suggesting habitat cuing in these sites. These results were affected by 27 squirrels remaining in the natal woodland that settled in the natal habitat type. Among emigrants $(n=33), 67 \%$ (2 of 3$)$ in CON, $0 \%(0$ of 5$)$ in $\mathrm{KH}$, and $24 \%$ (6 of 25) in SKW settled in the natal habitat type. In SKW the proportion of emigrants showing natal habitat type cuing was not different from expected (one-sample goodness-of-fit tests $\chi^{2}=0.12, d f=1, P=0.73$ ).

Emigrants that left the natal patch in SKW $(n=21)$ settled where density of the same sex was lower (mean difference of same-sex density \pm SE between natal and settlement patch $=0.15 \pm 0.04 / \mathrm{ha}$; Wilcoxon matchedpairs signed-ranks test $P=0.0006$ ). This was not due to squirrels emigrating to patches of lower quality (difference in woodland quality between natal and settlement patch $=-1.1 \pm 23.1$, Wilcoxon test $P=0.79$ ). We did not have density data for the post-dispersal areas in sites $\mathrm{CON}$ and $\mathrm{KH}$.

Survival

Thirty-eight squirrels (63\%) survived more than 6 months after dispersal. Local recruits (10 out of $15,67 \%$ ) were not more likely to survive than dispersers ( 28 out of $45,62 \%$; $\left.\chi^{2}=0.10, d f=1, P=0.76\right)$, and survival probability was not related to post-dispersal habitat quality $\left(\chi^{2}=1.75\right.$; $d f=1 ; P=0.19)$. There was no difference between study sites (CON 8 out of $10,80 \%$, KH 4 out of $9,44 \%$, SKW 26 out of $\left.41,63 \% ; \chi^{2}=2.44 ; d f=2 ; P=0.30\right)$. None of the other explanatory variables affected survival probability (all $P>0.30$ ).

\section{Discussion}

Spatial parameters from our three study sites (percentage forest cover, edge density and mean proximity index) showed different degrees of forest fragmentation: site CON was in a slightly fragmented landscape, KH and SKW in, respectively, medium and strongly fragmented landscapes.

Immature red squirrels dispersed over a wide range of distances: philopatric animals settled less than $100 \mathrm{~m}$ from the natal home range, while others emigrated over several kilometers (max. 4,118 m). Fifty percent dispersed more than $320 \mathrm{~m}$ away from the natal site, but less than $1.5 \mathrm{~km}$. The majority of red squirrels $(75 \%)$ dispersed from the 
natal site, independent of sex or study site, suggesting that, in this species, the proximate mechanism(s) causing dispersal did not change with degree of forest fragmentation monitored in this study. Thus, in agreement with previous studies $(20 \%$ of juveniles settling near the natal home range; Wauters et al. 1994c), squirrels were not more likely to settle near the natal home range with increasing forest fragmentation. Furthermore, there was no effect of degree of fragmentation on dispersal distances. Although 1 of 19 animals emigrated over more than $2 \mathrm{~km}$ in the less fragmented sites, $\mathrm{CON}$ and $\mathrm{KH}$, against 7 of 41 squirrels in the strongly fragmented site, SKW, there was no difference in distribution or average dispersal distance between sites with different landscape structure or composition (Table 3; Fig. 1), like Siberian flying squirrels (Pteromys volans, Hanski and Selonen 2009). Theoretically, habitat fragmentation can cause an increase as well as a decrease in dispersal distances, or can have no effect (Andrén 1994; Lima and Zollner 1996). An increase is expected for mobile species, with large perceptual ranges, when suitable habitat patches are rare and separated by vast areas of habitat unsuitable for settling but not for movements (e.g., Matthysen et al. 1995). In contrast, dispersal might be reduced with increasing fragmentation when suitable habitat patches are surrounded by a hostile matrix (barriers, urbanised areas, habitats with increased predation risk) (Sheperd and Swihart 1995). When matrix habitats are not hostile and do not reduce movements of relatively mobile species, different degrees of fragmentation will have little effect on dispersal behaviour and distances (Bakker and Van Vuren 2004; Gaillard et al. 2008). This was probably the case in our study, where suitable woodland patches were interspersed with farm- and cropland, isolated farms, houses with gardens and rural villages, all habitats that apparently did not reduce dispersal movements of red squirrels.

We found no effects of dispersal distance on survival: dispersers were as likely to survive over a 6-month period as squirrels that settled near the natal range. Also, previous studies on our species (Wauters et al. 1994b, c) and other sciurids did not find any short-term survival consequences of dispersal (Garrett and Franklin 1988; Van Vuren and Armitage 1994; Stuart-Smith and Boutin 1995; Haughland and Larsen 2004b; Hanski and Selonen 2009). We know of only two studies on sciurids that reported an increased mortality risk associated with dispersal. For North American red squirrels, increased predation during forays off the natal territory was probably balanced by offspring dispersing farther away being more likely to obtain a territory of higher quality (Larsen and Boutin 1994), and in arctic ground squirrels, mortality was positively related to distance from the natal territory (Byrom and Krebs 1999). In this study, we did find a higher 6-month survival in site
CON $(80 \%)$ than in the more fragmented sites $(63 \%$ in SKW, $44 \%$ in $\mathrm{KH}$ ), but these differences were not significant. These results suggest that reduced survival with increased fragmentation cannot explain lower immigration rates in fragmented versus larger woods (Wauters et al. 1994a). One reason might be that the dispersal patterns and survival rates revealed in this study were the result of a combination of food and population density over a relatively short period: this was particularly true for $\mathrm{CON}$ and $\mathrm{KH}$ where dispersers were monitored in only 1-2 years. Temporal variation in food abundance can play an important role in determining effects of habitat heterogeneity on dispersal rates and patterns (Haughland and Larsen 2004b; Clobert et al. 2009). However, in our study sites with more than 1 year of data (CON and SKW), there was no effect of annual variation in food abundance on dispersal distances.

There is accumulating evidence that dispersing individuals do not move randomly in a heterogeneous landscape, but that selection of post-dispersal (breeding) habitat relies upon information about their natal and future breeding environments and on the individual's phenotype (Clobert et al. 2009). In this study, 58\% of squirrels settled in the natal habitat type. However, in the less fragmented landscape, CON, natal habitat cuing was more pronounced ( $90 \%$ of squirrels showing natal habitat-biased dispersal against only 44 and $54 \%$ in other sites). However, the number of squirrels settling in the natal habitat type was higher than expected, based on the availability of each habitat type in the study site (see Table 2), in landscapes CON and SKW. It must be acknowledged that this habitat cuing is affected by $45 \%$ of squirrels settling within the natal wood and in the natal habitat type. In fact, if we only considered emigrants leaving the natal wood, 2 of 3 squirrels in CON showed habitat cuing, but no or few animals did so in the more strongly fragmented sites, $\mathrm{KH}$ and SKW. Hence, our data do not provide strong evidence for natal habitat cuing, but suggest a decrease in habitat cuing with increased forest fragmentation. Also, in dispersing flying squirrels (Selonen et al. 2007), the choice of settlement habitat in heterogeneous landscapes was influenced by some characteristics of the natal habitat (e.g., patch size), but not by others, such as habitat quality. In contrast, in North American red squirrels, natal habitatbiased dispersal was more pronounced than in this study, with the majority of juveniles from all habitats (with the exception of those living along the edge of mature forest) settling close to the natal territory and within their habitat of origin (Haughland and Larsen 2004a). These data on natal dispersal in other sciurids parallel those collected in this study, where dispersal outcomes are affected by a combination of experience in the natal habitat and opportunity of finding a suitable habitat for post-dispersal settlement. In our study, opportunity was determined by the 
local density of animals of the same sex. Both males and females settled in woodland patches where density of animals of the same sex was lower than in the natal patch (see also Wauters and Dhondt 1993). We concluded that increased habitat fragmentation seemed to reduce reliable cues for habitat choice, and that dispersing red squirrels settled in patches where density was lower than in the natal home range.

Acknowledgments We would like to thank all forest owners for their permission to study squirrels on their estates. Constructive criticism by two anonymous referees greatly helped to improve the MS. This study was partly financed by VLINA-project 97.01 of the Flemish Ministry (ANIMAL) and by the European Community (EC-Step-0040 project). Capturing, handling and radio-tracking of squirrels was done in compliance with national regulations.

\section{References}

Anderson PK (1989) Rodent dispersal. Spec Publ Am Soc Mammal 9:1-142

Andrén H (1994) Effects of habitat fragmentation on birds and mammals in landscapes with different proportions of suitable habitat: a review. Oikos 71:355-363

Bakker VJ, Van Vuren DH (2004) Gap-crossing decisions by the red squirrel, a forest-dependent small mammal. Conserv Biol 18:689-697

Byrom AE (2002) Dispersal and survival of juvenile feral ferrets Mustela furo in New Zealand. J Appl Ecol 39:67-78

Byrom AE, Krebs CJ (1999) Natal dispersal of juvenile arctic ground squirrels in the boreal forest. Can J Zool 78:1309-1319

Clobert J, Danchin E, Dhondt AA, Nichols JD (2001) Dispersal. Oxford University Press, Oxford

Clobert J, Gaillard JF, Cote J, Meylan S, Massot M (2009) Informed dispersal, heterogeneity in animal dispersal syndromes and the dynamics of spatially structured populations. Ecol Lett 12:197209

Coulon A, Fitzpatrick JW, Bowman R, Stith BM, Makarewich CA, Stenzler LM, Lovette IJ (2008) Congruent population structure inferred from dispersal behaviour and intensive genetic surveys of the threatened Florida scrub-jay (Aphelocoma corulescens). Mol Ecol 17:1685-1701

Davis JM, Stamps JA (2004) The effect of natal experience on habitat preferences. Trends Ecol Evol 19:411-416

Dobson FS, Jones WT (1985) Multiple causes of dispersal. Am Nat $126: 855-858$

Gaillard JM, Hewison AJM, Kjellander P, Pettorelli N, Bonenfant C, Van Moorter B, Liberg O, Andren H, Van Laere E, Klein F, Angibault JM, Coulon A, Vanpé C (2008) Population density and sex do not influence fine-scale natal dispersal in roe deer. Proc R Soc Lond B 275:2025-2030

Garrett MG, Franklin WL (1988) Behavioral ecology of dispersal in the black-tailed prairie dogs. J Mammal 69:236-250

Garshelis DL (2000) Delusions in habitat evaluation: measuring use, selection, and importance. In: Boitani L, Fuller TK (eds) Research techniques in animal ecology: controversies and consequences. Columbia University Press, New York, pp 111164

Greenwood PJ (1980) Mating system, philopatry and dispersal in birds and mammals. Anim Behav 28:1140-1162

Hale ML, Bevan R, Wolff K (2001) New polymorphic microsatellite markers for the red squirrel (Sciurus vulgaris) and their applicability to the grey squirrel (S. carolinensis). Mol Ecol Notes 1:47-49

Hanski IK, Selonen V (2009) Female-biased natal dispersal in the Siberian flying squirrel. Behav Ecol 20:60-67. doi:10.1093/ beheco/arn115

Haughland DL, Larsen KW (2004a) Ecology of North American red squirrels across contrasting habitats: relating natal dispersal to habitat. J Mammal 85:225-236

Haughland DL, Larsen KW (2004b) Exploration correlates with settlement: red squirrel dispersal in contrasting habitats. J Anim Ecol 73:1024-1034

Hosmer DW, Lemeshow S (1989) Applied logistic regression. Wiley, London

Jenness J (2007) Nearest features (nearfeat.avx) estension for ArcView 3.x v. 3.8b. Jenness Enterprises. http://jennessent.com/ arcview/nearest_features.htm

Larsen KW, Boutin S (1994) Movements, survival, and settlement of red squirrel (Tamiasciurus hudsonicus) offspring. Ecology 75:214-223

Lima SL, Zollner PA (1996) Towards a behavioral ecology of ecological landscapes. Trends Ecol Evol 11:131-135

Locey KJ, Stone PA (2008) Ontogenetic factors affecting diffusion dispersal in the introduced Mediterranean gecko, Hemidactylus turcicus. J Herpetol 42:593-599

Marshall TC, Slate J, Kruuk LEB, Pemberton JM (1998) Statistical confidence for likelihood-based paternity inference in natural conditions. Mol Ecol 7:639-655

Matthysen E (2005) Density-dependent dispersal in birds and mammals. Ecography 28:403-416

Matthysen E, Currie D (1996) Habitat fragmentation reduces disperser success in juvenile nuthatches Sitta europaea: evidence from patterns of territory establishment. Ecography 19:67-72

Matthysen E, Adriaensen F, Dhondt AA (1995) Dispersal distances of nuthatches, Sitta europaea, in a highly fragmented forest habitat. Oikos 72:375-381

McGarigal K, Marks BJ (1994) Fragstats: spatial pattern analysis program for quantifying landscape structure. Version 2.0. Forest Science Department. Oregon State University, Corvallis

Pulliam HR, Danielson BJ (1991) Sources, sinks, and habitat selection: a landscape perspective on population dynamics. Am Nat 137:S50-S66

Remeš V (2000) How can maladaptive habitat choice generate source-sink population dynamics? Oikos 91:579-582

SAS (1999) SAS/STAT user's guide, version 8.2. SAS Institute, Cary

Schiegg K, Daniels SJ, Walters JR, Priddy JA, Pasinelli G (2006) Inbreeding in red-cockaded woodpeckers: effects of natal dispersal distance and territory location. Biol Conserv 131:544-552. doi:10.1016/j.biocon.2006.03.001

Schlaepfer MA, Runge MC, Sherman PW (2002) Ecological and evolutionary traps. Trends Ecol Evol 17:474-481

Selonen V, Hanski IK, Desrochers A (2007) Natal habitat-biased dispersal in the Siberian flying squirrel. Proc R Soc Lond B 274:2063-2068

Sheperd BF, Swihart RK (1995) Spatial dynamics of fox squirrels (Sciurus niger) in fragmented landscapes. Can J Zool 73:20982105

Stamps JA (1987) The effect of familiarity with a neighborhood on territory acquisition. Behav Ecol Sociobiol 21:274-277

Stenseth NC, Lidicker WZ (1992) Animal dispersal: small mammals as a model. Chapman \& Hall, London

Stuart-Smith AK, Boutin S (1995) Behavioral differences between surviving and depredated juvenile red squirrels. Ecoscience 2:34-40

Szulkin M, Sheldon BC (2008) Dispersal as a means of inbreeding avoidance in a wild bird population. Proc R Soc Lond B 275:703-711. doi:10.1098/rspb.2007.0989 
Todd R (2000) Microsatellite loci in the Eurasian red squirrel, Sciurus vulgaris L. Mol Ecol 9:2165-2166

Travis JMJ, French DR (2000) Dispersal functions and spatial models: expanding our dispersal toolbox. Ecol Lett 3:163-165

Trizio I, Crestanello B, Galbusera P, Wauters LA, Tosi G, Matthysen E, Hauffe HC (2005) Geographical distance and physical barriers shape the genetic structure of Eurasian red squirrels (Sciurus vulgaris) in the Italian Alps. Mol Ecol 14:469-481

Turchin P (1998) Quantitative analysis of movement: measuring and modeling population redistribution in animals and plants. Sinauer, Sunderland

Van Vuren D, Armitage KB (1994) Survival of dispersing and philopatric yellow-bellied marmots: what is the cost of dispersal? Oikos 69:179-181

Verbeylen G, De Bruyn L, Mattysen E (2003) Patch occupancy, population density and dynamics in a fragmented red squirrel Sciurus vulgaris population. Ecography 26:118-128

Verbeylen G, Wauters LA, De Bruyn L, Matthysen E (2009) Woodland fragmentation affect space use of Eurasian red squirrels. Acta Oecol 35:94-103. doi:10.1016/j.actao.2008.08.005

Vuilleumier S, Fontanillas P (2007) Landscape structure affects dispersal in the greater white-toothed shrew: inference between genetic and simulated ecological distances. Ecol Model 201:369-376

Wauters LA, Casale P (1996) Long-term scatterhoarding in the red squirrel (Sciurus vulgaris). J Zool 238:195-207

Wauters LA, Dhondt AA (1992) Spacing behaviour of the red squirrel, Sciurus vulgaris: variation between habitats and the sexes. Anim Behav 43:297-311
Wauters LA, Dhondt AA (1993) Immigration patterns and success in red squirrels. Behav Ecol Sociobiol 33:159-167

Wauters LA, Dhondt AA (1995) Lifetime reproductive success and its correlates in female Eurasian red squirrels. Oikos 72:402-410

Wauters LA, De Vos R, Dhondt AA (1990) Factors affecting male mating success in red squirrels (Sciurus vulgaris). Ethol Ecol Evol 2:195-204

Wauters L, Hutchinson Y, Parkin DT, Dhondt AA (1994a) The effects of habitat fragmentation on demography and on the loss of genetic variation in the red squirrel. Proc R Soc Lond B 255:107-111

Wauters L, Matthysen E, Dhondt AA (1994b) Survival and lifetime reproductive success in dispersing and resident red squirrels. Behav Ecol Sociobiol 34:197-201

Wauters LA, Casale P, Dhondt AA (1994c) Space use and dispersal of red squirrels in fragmented habitats. Oikos 69:140-146

Wauters LA, Lens L, Dhondt AA (1995) Variation in territory fidelity and territory shifts among red squirrels, Sciurus vulgaris, females. Anim Behav 49:187-193

Wauters LA, Matthysen E, Adriaensen F, Tosi G (2004) Within-sex density dependence and population dynamics of red squirrels Sciurus vulgaris. J Anim Ecol 73:11-25

Wiens JA, Stenseth NC, Van Horne B, Ims RA (1993) Ecological mechanisms and landscape ecology. Oikos 66:369-380

Wolff JO (1994) More on juvenile dispersal in mammals. Oikos 71:349-352 